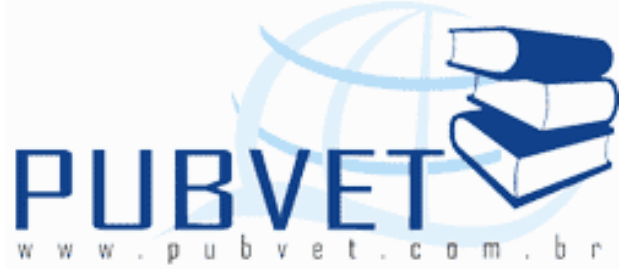

PUBVET, Publicações em Medicina Veterinária e Zootecnia.

\title{
Efeito de diferentes sistemas de pastejo em atributos físicos do solo $^{1}$
}

Karina Ferro Cervelati ${ }^{2}$, Eurico Lucas de Sousa Neto ${ }^{3}$, Edson Sadayuki Eguchi ${ }^{4}$, Mérik Rocha Silva ${ }^{4}$ e Maria Aparecida Pereira Pierangeli ${ }^{4}$

${ }^{1}$ Trabalho de Conclusão de Curso do Primeiro Autor.

2 Autora, Zootecnista - UNEMAT, kacervelati@hotmail.com.

3 Professor Orientador, euricolucas@yahoo.com.br.

${ }^{4}$ Colaboradores, edeguchi@yahoo.com,mapp@unemat.br,merikrocha@hotmail.com.

\section{Resumo}

Em vista de que é importante a interação solo-clima-planta-animal para se alcançar boas produtividades nos sistemas de produção, o objetivo deste estudo foi avaliar as alterações nos atributos físicos do solo provocado por sistemas de pastejo contínuo e rotacionado. Os sistemas de uso foram: convencional (CC): Brachiaria brizantha cv. BRS Piatã, sem adubação anual de reposição, manejado em sistema de lotação contínua; adubado (AD): Brachiaria brizantha cv. BRS Piatã manejado em sistema de lotação rotacionado, com a adubação anual de reposição com N-P-K na proporção de 45-20-20 kg ha-1 ano ${ }^{-1}$; e consorciado (CS): consórcio de Brachiaria brizantha cv. BRS Piatã e Stylosanthes Campo Grande, manejados em sistema de lotação rotacionado, recebendo adubação anual de reposição com N-P-K de 00-20-20 kg ha-1 ano-1. Para avaliar o efeito 
do pisoteio animal nos sistemas foram coletados anéis com amostras de solo com estrutura indeformada nas camadas de 0,00 - 0,06 m e 0,06 0,12 m antes e após o pastejo para as determinações de densidade do solo pelo método do anel volumétrico, macroporosidade, microporosidade e porosidade total, pelo método da mesa de tensão, foram coletadas também amostras com estrutura deformada na mesma camada para a determinação do teor de matéria orgânica. A resistência do solo à penetração foi determinada antes e após o pastejo nas profundidades de $0,0-0,1,0,1-0,2,0,2-0,3$ e 0,3 - 0,4 m, com o penetrômetro de impacto. O pisoteio animal alterou somente a microporosidade; a utilização de diferentes sistemas de cultivo e pastejo não promoveram diferenças em relação ao teor de matéria orgânica. Os solos do sistema de pastejo convencional apresentaram maior tendência à compactação do solo avaliada pela resistência mecânica a penetração de raízes.

Palavras-chave: compactação, pisoteio animal, resistência do solo à penetração

\section{Abstract}

In view of the importance of the interaction soil-climate-plant-animal to attain good yields in the system, the objective of this study is to evaluate changes in soil physical properties caused by grazing systems continuous and rotated. The systems were used: conventional (CC): Brachiaria brizantha CV. BRS Piatã, unfertilized annual replacement, managed under continuous stocking; fertilizer (AD): Brachiaria brizantha cv. BRS Piatã managed under rotational stocking system, with annual replacement fertilization with NPK at a ratio of 45-20-20 kg ha ${ }^{-1} \mathrm{year}^{-1}$, and intercropping (IC): Consortium of Brachiaria brizantha cv. BRS Piatã and Stylosanthes Campo Grande, managed in a rotational system of stocking, fertilization receiving annual replacement with 00-20-20 NPK kg ha-1 year${ }^{1}$. To evaluate the effect of animal trampling on systems with rings were collected soil samples with undisturbed layers from $0.00-0.06 \mathrm{~m}, 0.06$ $0.12 \mathrm{~m}$ before and after grazing for the determination of soil density by 
the volumetric ring method, macroporosity and total porosity by the method of the tension table, were also collected samples deformed structure in the same layer for determining the organic matter content. The resistance to penetration was determined before and after grazing in the depths of $0.0-0.1,0.1-0.2,0.2-0.3$ and $0.3-0.4 \mathrm{~m}$, with the impact penetrometer. Animal stepping changed only the microporosity, the use of different cropping systems and grazing no differences in relation to organic matter content. The soils of the conventional grazing system were more tendency to soil compaction measured by penetration resistance of roots.

Keywords: compaction, animal trampling, soil resistance to penetration 


\section{AGRADECIMENTOS}

À Deus, porque em todos os lugares e todas as coisas ele sempre está presente para me proteger e orientar os meus passos.

À minha família, por todo o apoio, confiança e dedicação para a conquista desse sonho.

À Universidade do Estado de Mato Grosso, por ter possibilitado a realização deste trabalho.

Ao Professor Msc. Eurico Lucas de Sousa Neto, a quem sou muito grata por não medir esforços para me ajudar sempre que precisei, por ter participado da minha formação acadêmica, orientar e auxiliar no desenvolvimento do meu conhecimento científico e profissional, e pela confiança e apoio em todos os momentos.

Ao Msc. Rodrigo Froede Ruppin por permitir a realização deste trabalho na área de seu experimento.

Ao Departamento de Zootecnia e aos professores do Curso de Zootecnia: Dra . Jocilaine Garcia; Msc. Giulianna Zilocchi Miguel, Dr. Alexandre Agostinho Mexia; Msc. Edson Sadayuki Eguchi, Dr. Luiz Juliano Valério Geron, Dr ${ }^{\mathrm{a}}$. Maria Aparecida Pereira Pierangeli, Msc. Marcelo Pinheiro da Silva Meireles, Tatiane Botini, Maurício Arantes Vargas, Msc. Giselde Marques Angreves Silva, Msc. Lourival da Silva Júnior, Osvaldo M. Souza, Drª Adriana F. B. Mexia e demais professores pela paciência e pelos valiosos ensinamentos.

Aos funcionários do Departamento de Zootecnia e do laboratório de Análise de Solos.

Ao colega Eurides Ventura Gonçalves e ao amigo Renato Tonhá Alves Júnior que contribuíram na execução deste trabalho.

Aos meus amigos Tatiane Martinhão Pás, Daniely Araújo Freitas, Beatriz Lacerda Carvalho, Thayná Barcelos Fernandes, Suelen Correa da Silva, e Gheany Roberta Leal por compartilharem os momentos de luta e lazer.

À Danilo Novaes Rodrigues, um homem muito especial em minha vida. 
“...Hoje me sinto mais forte, mais feliz quem sabe Só levo a certeza de que muito pouco eu sei Nada sei... Cada um de nós compõe a sua história Cada ser em si carrega o dom de ser capaz E ser feliz..." (Renato Teixeira) 


\section{SUMÁRIO}

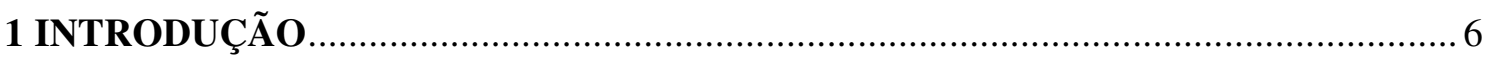

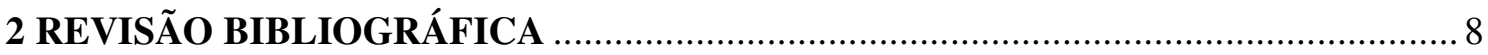

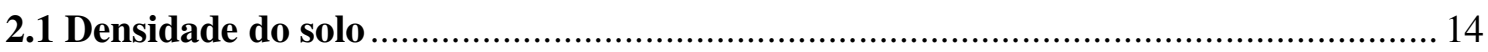

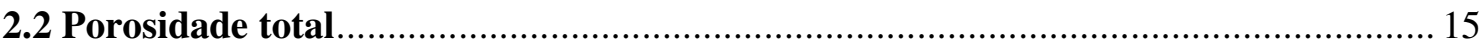

2.3 Resistência mecânica do solo à penetração .......................................................... 15

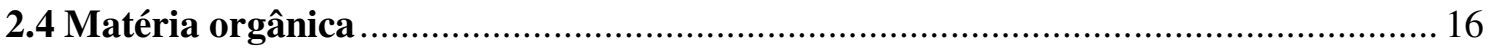

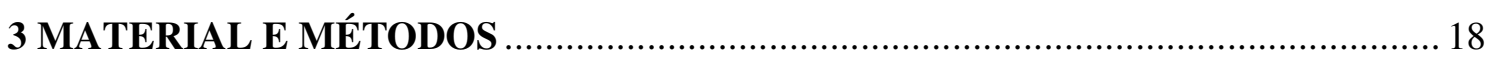

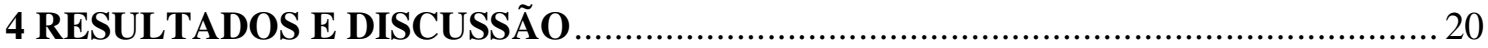

5 CONCLUSÃO

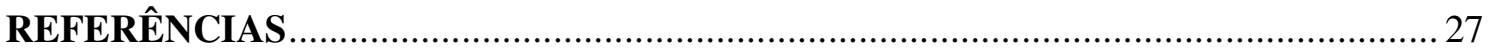




\section{INTRODUÇÃO}

O bom crescimento e desenvolvimento das plantas, os quais as levam a produzir grãos, fibras e outros produtos comerciáveis, dependem da harmonia de uma série de fatores ambientais. A absorção de nutrientes é um dos fatores importantes para que se tenha boas produções, e pode-se dizer que qualquer obstáculo que restrinja o crescimento radicular reduz tal absorção (CAMARGO e ALLEONI, 2006).

Um dos grandes entraves na obtenção de elevadas produtividades tem sido a compactação do solo (LIMA et al., 2004). A compactação do solo, dependendo da sua intensidade, pode causar restrição ao desenvolvimento radicular e afetar a produção das plantas, e, consequentemente, a produção animal.

A redução da produtividade das pastagens tem sido relacionada ao manejo inadequado da fertilidade do solo, das espécies forrageiras exploradas, da taxa de lotação animal, que podem comprometer a qualidade física do solo (FIDALSKI et al., 2008), e prejudicar o desenvolvimento e produtividade das pastagens.

O solo suporta a vegetação segundo as suas condições químicas, biológicas e físicas e a vegetação mantém o gado. $\mathrm{O}$ gado modifica a vegetação pelo pisoteio, pelo pastejo preferencial ou rejeição de plantas, pelo modo de colher as plantas, pela frequiência com que as procura e por suas excreções (PRIMAVESI, 1999).

A qualidade física do solo é importante para a fertilidade do solo, visto que condiciona a disponibilidade de ar e água para as plantas, assegurando, ainda, o transporte de elementos nutritivos em solução, além de influenciar a infiltração e distribuição da água dentro do solo que tem, por sua vez, papel importante no controle da erosão hídrica (TAVARES FILHO et al., 2005).

De acordo com Reichert et al. (2003), a qualidade física do solo está associada ao solo que: permite a infiltração, retenção e disponibilização de água às plantas; responde ao manejo e resiste à degradação; permite as trocas de calor e de gases com a atmosfera e raízes de plantas; e permite o crescimento das raízes.

A qualidade física do solo não pode ser medida diretamente, mas é avaliada pelos atributos físicos do solo, tais como: densidade, porosidade e resistência do solo à penetração que influenciam no desenvolvimento radicular e consequentemente na produção das plantas. O manejo inadequado do solo, principalmente sob intenso pisoteio animal, pode acarretar mudanças na estrutura física do solo, reduzindo seu volume e aumentando a densidade do 
solo, resultando na sua compactação. Sendo assim, é importante o seu acompanhamento através dos atributos físicos como parâmetros para identificar problemas de manejo e assim adequar o sistema para proporcionar boas condições físicas para desenvolvimento e produção das pastagens e, assim, alcançar boas produtividades animal.

Para Freitas (1994) a compactação do solo é considerada a maior limitação à alta produtividade das culturas em todo o mundo, pois afeta diretamente o crescimento de raízes, diminui a capacidade de infiltração de água no solo e reduz a translocação de nutrientes, resultando em uma pequena camada para ser explorada pelas raízes. Em solo compactado o sistema radicular concentra-se próximo à superfície, tornando a planta mais susceptível a déficits hídricos e com limitada capacidade de absorver nutrientes em camadas subsuperficiais (ROSOLEM et al., 1994). A compactação do solo tem sido apontada como um dos principais problemas evidenciados nas áreas sob pastejo intensivo, pois tem causado a diminuição da produção de forragem das pastagens cultivadas. O impacto causado pelo pisoteio bovino sobre o solo e os conseqüentes reflexos sobre alguns atributos físicos, tem sido atribuído ao fato de seu peso ser distribuído em uma menor área atingida pelo seu casco (RODRIGUES JUNIOR, 2009).

Em vista de que é importante a interação solo-clima-planta-animal para se alcançar boas produtividades no sistema, o objetivo deste estudo é avaliar as alterações nos atributos físicos do solo provocado por sistemas de pastejo contínuo e rotacionado. 


\section{REVISÃO BIBLIOGRÁFICA}

O solo é o principal substrato para produção de alimentos funcionando não somente no sistema de produção agrícola, mas também na manutenção da qualidade ambiental (DIAS e MELLO, 1998). O estudo do solo é necessário, pois sua conservação e manutenção são para garantir seu potencial produtivo em longo prazo. Sendo assim, o uso de indicadores da qualidade do solo para avaliação da sustentabilidade ambiental é de grande importância (MENDES et al., 2006).

O solo em sua constituição física apresenta as principais propriedades: textura, estrutura, porosidade, densidade, densidade de partículas, quantidade de água no solo (umidade gravimétrica) e resistência mecânica à penetração de raízes. Essas propriedades permitem uma avaliação do estado de conservação do solo (OLIVEIRA NOBRE, 2008), exceto a textura e densidade de partículas.

Os estudos dos atributos físicos podem apontar para uma ação diferenciada dos processos de manejo, pois são de grande importância na análise do comportamento das culturas empregadas, já que as características físicas e químicas do solo são diretamente afetadas pelo tipo de manejo a que ele é submetido (FERNANDES e SOUZA, 2001).

Nas últimas décadas as alterações dos atributos que ocasionam a degradação dos solos têm sido detectadas de forma intensa em áreas agrícolas, em razão de diversos processos que levam ao depauperamento das características físicas, químicas e biológicas, sendo apontados como responsáveis o revolvimento excessivo do solo em áreas agrícolas, as práticas agrícolas inadequadas e o superpastejo. Esses processos são responsáveis por diversos fatores que têm contribuído para a diminuição do potencial produtivo do solo, o que tem afetado a sustentabilidade do sistema (AZEVEDO e SVERZUT, 2007).

A compactação do solo é uma alteração estrutural, na qual ocorre uma reorganização das partículas e de seus agregados, resultando no aumento da densidade do solo e redução da porosidade total e da macroporosidade do solo. A compactação do solo reduz o volume de macroporos enquanto os microporos permanecem praticamente inalterados, diminuindo as taxas de infiltração e da condutividade hidráulica do solo (STONE et al., 2002). Isso afeta negativamente a aeração, a mineralização mais lenta da matéria orgânica, a disponibilidade e absorção de água e de nutrientes pelas plantas, o fluxo de $\mathrm{CO}_{2}$ e dos nutrientes no solo (ALVARENGA et al., 1996), e o desenvolvimento do sistema radicular e da parte aérea. 
A utilização de sistemas de manejo do solo que envolva pastejo animal pode acarretar mudanças nos atributos físicos, químicos e biológicos do solo, o que pode afetar o crescimento e desenvolvimento radicular e a produção das culturas implantadas na sequiência do pastejo (SILVA et al., 2000). A magnitude dessas alterações, principalmente nos atributos físicos do solo, está na dependência do manejo que é aplicado nas áreas sob pastejo, podendo variar com a textura, o teor de matéria orgânica, o teor de umidade do solo (TREIN et al., 1991), a biomassa vegetal sobre o solo (SILVA et al., 2000, 2003), a espécie de planta, a intensidade e tempo de pastejo e a espécie e categoria animal (CORREA e REICHARDT, 1995).

O grau de compactação provocado pelo pisoteio bovino é influenciado pela textura do solo, sistema de pastejo, altura de manejo da pastagem (CASSOL, 2003) e quantidade de resíduo vegetal sobre o solo (BRAIDA et al., 2004) e umidade do solo, o que evidencia a importância do controle das taxas de lotação animal, em relação à quantidade de pastagem produzida e à manutenção de cobertura vegetal adequada sobre os solos, a fim de mitigar esse efeito do pisoteio sobre a qualidade física dos solos (SARMENTO et al., 2008). No entanto, o efeito do pisoteio animal sobre as propriedades físicas do solo é limitado às suas camadas mais superficiais (TREIN et al., 1991), podendo ser temporário e reversível (CASSOL, 2003).

Segundo Muller et al. (2001), a deterioração das condições físicas de solos sob pastagem foi atribuída ao pisoteio do gado, que causou compactação, expressa pelo aumento da densidade, da resistência do solo à penetração, e da redução do espaço poroso total, da macroporosidade e dos valores das propriedades hidráulicas, o que propiciou menor capacidade de infiltração da água no solo e aumento da susceptibilidade a erosão. Cabe ressaltar que, quando a carga animal é manejada adequadamente, as alterações nos atributos físicos são pequenas e não causam qualquer dano à pastagem ou culturas subsequentes (ALBUQUERQUE et al., 2001a).

Para Leão et al. (2003) o impacto dos sistemas de pastejo sobre as propriedades físicas tem sido subestimado por parte de técnicos e produtores. Leonel et al. (2003) reforçaram que a área de pastagem no Brasil necessita de maiores informações de manejo e conservação do solo, em razão de que a degradação das pastagens e a redução da sua capacidade de suporte podem estar associadas a vários fatores, dentre eles, as classes de solos e seu manejo, as espécies forrageiras e as condições climáticas. Desta forma, são necessários estudos que caracterizem as alterações dos solos sob pastagens, cujo objetivo seja o entendimento das modificações físicas e químicas que sofrem os solos após a retirada da vegetação original para o estabelecimento da pastagem (AZEVEDO e SVERZUT, 2007). 
A avaliação dos efeitos do pisoteio animal sobre as características e propriedades físicas do solo são geralmente baseadas na mensuração de alguns parâmetros físicos do solo, dentre os quais se destacam a densidade, a macroporosidade, a microporosidade, a taxa de infiltração de água e a resistência à penetração de raízes. Adequadas condições de espaço poroso do solo para o bom desenvolvimento de plantas caracterizam-se por uma boa porosidade e equilibrada distribuição de diâmetros de poros entre microporos e macroporos. Contudo, é bastante difícil manter as boas condições físicas do solo, uma vez que a utilização de implementos e máquinas, assim como o pisoteio animal causam deterioração no espaço poroso através de pressões que são aplicadas sobre o solo (FLORES, 2007).

A pressão do casco dos animais sobre o solo pode comprometer a qualidade física na camada superficial, em razão do aumento da densidade do solo e da redução da porosidade (GIAROLA et al., 2007). Um bovino de $400 \mathrm{~kg}$ exerce uma pressão de $3,5 \mathrm{~kg} / \mathrm{cm}^{2}$ (PRIMAVESI, 1999).

O aumento da pressão de pastejo, relação entre o peso animal e a massa de forragem disponível $\left[\mathrm{kg}_{\text {(animal) }} \mathrm{kg}^{-1}\right.$ (massa seca de forragem) $\mathrm{dia}^{-1}$ ], em conseqüência do aumento da taxa de lotação animal em pastagens de baixa produtividade, compromete a qualidade física do solo, pois resulta em maior carga de animais sobre o solo (Silva et al., 2003), independentemente do sistema de produção (pastejo rotacionado, contínuo e integração lavoura-pecuária), conforme Lanzanova et al. (2007).

Uma excessiva taxa de lotação animal determina a redução na qualidade física e estrutural do solo sob pastagens. $\mathrm{O}$ descanso da pastagem possibilita a recuperação parcial da qualidade física do solo, atribuída aos efeitos positivos do crescimento radicular e da micro e mesofauna do solo em associação com os efeitos de secamento e umedecimento sobre a estrutura do solo (DA SILVA et al.2002)

Um aspecto a ser considerado no estudo de compactação do solo é que os impactos causados por trafego de máquinas e, principalmente, dos animais pode ser reduzido pela presença da cobertura do solo (COSTA, 2000). Segundo Dias Filho (1998), pastos formados com espécies cujo hábito de crescimento não proporciona eficiente cobertura do solo e que são relativamente exigentes em fertilidade são normalmente mais suscetíveis à degradação precoce que os pastos formados com gramíneas com hábito de crescimento decumbente e menos exigentes em fertilidade do solo.

Imhoff et al. (2000) defendem que a compactação causada pelo pisoteio dos animais concorre para a redução da produtividade e longevidade das pastagens. Em geral, a maior pressão de pastejo resulta em aumento da densidade do solo e redução da porosidade e da 
estabilidade dos agregados em água na camada superficial, o que causa a degradação da pastagem.

Os animais influem sobre o solo diretamente pelo pisoteio, que é muito mais prejudicial em épocas muito úmidas e muito secas. Mas influi também indiretamente, através do pastejo seletivo, desnudando manchas de chão onde se assenta a erosão, e pelo pastejo freqüente que diminui o tamanho das raízes e contribui para o adensamento do solo. A compactação depende da umidade do solo, da cobertura vegetal existente (plantas com raízes profundas sofrem menos) e da vegetação viva ou morta. Nas épocas muito secas o pisoteio é tão prejudicial que, em épocas muito chuvosas, a compactação pode atingir até $11 \mathrm{~cm}$ de profundidade. Mas como o gado de cria e o gado leiteiro exportam nutrientes, o solo empobrece, e com ele a vegetação, o que dá margem a uma decadência química e consequentemente física do solo (PRIMAVESI, 1999).

Condições físicas do solo adequadas ao crescimento das plantas resultam de complexas interações entre resistência do solo à penetração (RP), aeração e disponibilidade de água, as quais afetam diretamente o crescimento das plantas (TORMENA et al. 2007). A resistência do solo à penetração é um índice integrado pela densidade do solo, textura, matéria orgânica e umidade do solo (TORMENA et al., 2004).

Normalmente, as determinações de densidade e de porosidade do solo são as avaliações mais comuns e difundidas para identificar camadas compactadas no solo, porém a resistência mecânica deste à penetração também está diretamente relacionada com o estado de compactação do solo e pode ser uma medida mais sensível para identificar a compactação, especialmente em camadas pouco espessas (ABREU et al., 2004). O monitoramento periódico do estado de compactação do solo por meio da resistência à penetração é uma forma prática de avaliação dos efeitos dos diferentes sistemas de manejo na estrutura do solo e no crescimento radicular das diferentes culturas, permitindo assim pesquisas e avaliações na propriedade rural (TAVARES FILHO e RIBON, 2008).

Em solos mais argilosos, o aumento da densidade do solo e da resistência do solo à penetração pode ser mais restritivo às raízes do que em solos arenosos (ALBUQUERQUE et al. 2001b).

A resistência do solo à penetração das raízes está relacionada com a permanência da continuidade dos poros. Poros formados pela ação das raízes no solo são mais estáveis, pois a decomposição dessas por microrganismos gera materiais que atuam como cimentantes nas paredes desses poros, proporcionando maior durabilidade, se comparados com aqueles formados por implementos mecânicos (ABREU, 2000). 
A utilização de áreas com pastagens tem assumido destaque em razão da elevada proporção que tem ocupado em relação ao total das áreas agrícolas, aliado ao fato das estimativas apontarem que a maioria das áreas degradadas, em nível mundial, esta sob pastagens (AZEVEDO e SVERZUT, 2007). A degradação das pastagens afeta diretamente a sustentabilidade da pecuária. Considerando apenas a fase de recria e engorda de bovinos, a produção animal em uma pastagem degradada pode ser seis vezes inferior à de uma pastagem recuperada ou em bom estado de manutenção (MACEDO et al., 2000).

As pastagens cultivadas destinadas à criação de bovinos, embora em sua maioria proporcionem boa cobertura de solo, vem sendo utilizadas com lotações inadequadas em relação a sua capacidade de produção e as características do solo. As propriedades físicas do solo necessitam ser monitoradas em função da oferta de forragem, pois variando-se os níveis de oferta de forragem obtêm-se diferentes níveis de pressões de pastejo, em que se avalia a real capacidade de produção animal das pastagens. Assim, pode-se buscar o ponto ótimo de oferta de forragem, no qual é possível maximizar os ganhos por animal e por área, e manter pastagens com boa qualidade. Sendo assim, é importante detectar o nível crítico de oferta de forragem, equivalente a uma pressão de pastejo crítica, acima do qual as propriedades físicas do solo podem sofrer alterações indesejáveis, pois a intensidade de desfolhação das pastagens e a pressão de pastejo ocasionadas pelo pisoteio dos animais são distintas nos diferentes níveis de oferta de forragem (BERTOL et al., 2000).

Atributos físicos do solo favoráveis ao crescimento do sistema radicular são necessários para a obtenção e manutenção de elevadas produtividades. Os solos devem possuir suficiente espaço poroso para o movimento de água e gases e resistência favorável à penetração das raízes. Neste contexto, a compactação causada pelo pisoteio dos animais concorre para a redução da produtividade e longevidade das pastagens (SANTANA, 2009).

O crescimento do sistema radicular e da parte aérea das plantas é influenciado por vários atributos físicos do solo, com complexas interações que envolvem o potencial da água no solo, o teor de oxigênio e a resistência do solo à penetração das raízes (TORMENA et al., 1998), fatores que dificultam a obtenção de valores críticos ao desenvolvimento e produtividade das culturas (BEUTLER et al., 2004). Segundo Silva et al. (2006), a densidade da camada compactada capaz de limitar o crescimento das plantas varia conforme a classe de solo, condições de umidade, espécie e ou mesmo do cultivar plantado.

Segundo Flores (2004) algumas espécies de plantas têm a capacidade de desenvolver um sistema radicular mais agressivo, capaz de romper camadas compactadas de solo. Entretanto, a maioria das culturas comerciais exploradas apresenta um sistema radicular 
sensível à compactação. Camargo e Alleoni (1997) denominam "plantas descompactadoras" aquelas que apresentam raízes com capacidade elevada de penetração em camadas de solo com alta impedância mecânica. $\mathrm{O}$ alongamento radicular só é possível quando a pressão de crescimento das raízes for maior do que a resistência mecânica do solo à penetração.

Geralmente predominam as plantas que melhor suportam o pisoteio e as tosas freqüentes, e desaparecem as que necessitam de maior tempo para sua recuperação. A maioria das forrageiras cultivadas exige um solo mais ou menos solto. Em pastagens mistas a compactação é menor graças aos sistemas radiculares diferentes. Especialmente leguminosas conseguem manter o solo aberto (PRIMAVESI, 1999).

O crescimento das raízes se dá por divisão e expansão das células meristemáticas e, com isso, a raiz penetra no solo. Desta forma, o crescimento está baseado principalmente no turgor das células radiculares. Se a resistência oferecida pelo solo for superior a essa força, o crescimento radicular é bastante prejudicado, podendo até mesmo cessar. O crescimento radicular é o parâmetro mais adequado para a avaliação do impedimento ao crescimento de plantas sobre solos compactados (MELLO, 2002).

A rota preferencial de crescimento das raízes é através dos macroporos (CAMARGO E ALLEONI, 1997). Deste modo, em solos compactados, em que há diminuição dos macroporos, o desenvolvimento radicular pode ser prejudicado, conforme salientado por Silva et al. (2000). A redução na macroporosidade, por afetar o movimento de água no solo e a dinâmica de gases, é considerada por Mello (2002) como o principal efeito danoso do pisoteio animal sobre o solo.

O sistema radicular provoca desarranjos no solo ao penetrar camadas com alta resistência mecânica e, ao sofrer decomposição, deixa canais ("bioporos") que contribuem para a infiltração de água e difusão de gases, melhorando a qualidade física do solo para as culturas subseqüentes. Além disso, o crescimento radicular pode incrementar a matéria orgânica ao longo do perfil do solo, a qual promove a estabilização dos agregados, reduzindo a susceptibilidade do solo à compactação (ROTH et al., 1992).

Em solo compactado, o sistema radicular concentra-se próximo à superfície, tornando a planta mais susceptível a déficits hídricos e limitando sua capacidade de absorver nutrientes em camadas subsuperficiais (MULLER et al., 2001).

Contudo, a influência da compactação sobre as plantas depende da espécie, do tipo de solo e do teor de água no solo. A compactação do solo, em magnitude moderada, pode apresentar efeitos benéficos tais como melhoria do contato solo-semente e raiz, favorecendo a 
absorção de água e de nutrientes pelas plantas, e aumento da disponibilidade de água em anos secos (DIAS JUNIOR e PIERCE, 1996).

Considerando a reciclagem de minerais em um ecossistema da pastagem, a união com o solo assume importância crucial. Assim, é importante considerar a interação solo-plantaanimal no contexto da ecologia do pasto (NASCIMENTO JR., 1998). As plantas obtêm os nutrientes que necessitam através da absorção, pelas raízes, dos elementos existentes na solução do solo. A compactação do solo, afetando o desenvolvimento dos organismos do solo, pode resultar em um decréscimo na quantidade de nutrientes mineralizados provenientes da matéria orgânica do solo alterando o processo de reciclagem dos elementos, o que reduziria o fornecimento às plantas e, conseqüentemente, a produtividade do sistema (COSTA, 2000).

\subsection{Densidade do solo}

A densidade do solo é também chamada de densidade global ou densidade aparente, sendo bastante afetada pelo manejo do homem sobre o solo (ANDRADE et al., 1998).

A densidade do solo pode ser modificada continuamente pelo uso da terra e é influenciada pelo manejo. A utilização de máquinas e equipamentos pesados e elevada carga animal, favorece o seu aumento (BERTOL et al., 2006).

A densidade do solo depende da natureza, das dimensões e da forma como se acham dispostas as partículas do solo. Nos solos minerais os valores da densidade do solo oscilam de 1,1 a $1,6 \mathrm{~g} \mathrm{~cm}^{-3} \mathrm{e}$, no solos orgânicos, a densidade é inferior, achando-se entre 0,6 a $0,8 \mathrm{~g} \mathrm{~cm}^{-3}$ A amplitude de variação situa-se dentro dos limites médios: solos argilosos, de 1,00 a 1,25 g $\mathrm{cm}^{-3}$; solos arenosos de 1,25 a 1,40 $\mathrm{g} \mathrm{cm}^{-3}$; solos humíferos, de 0,75 a $1,00 \mathrm{~g} \mathrm{~cm}^{-3}$ e solos turfosos, de 0,20 a 0,40 $\mathrm{g} \mathrm{cm}^{-3}$ (SANTANA, 2009).

De maneira geral, pode-se afirmar que, quanto mais elevada for à densidade do solo, maior será a sua compactação, menor será a sua estruturação, menor a sua porosidade total e, conseqüentemente, maiores serão as restrições para o crescimento e desenvolvimento das plantas (RABELO, 2000). 


\subsection{Porosidade total}

A porosidade depende, principalmente, da textura e da estrutura dos solos. A porosidade de um solo pode ser definida como o volume de vazios. Esta é a relação entre a proporção de espaços que podem ser ocupados por líquidos e ar em relação ao espaço ocupado pela massa de solo (SANTANA, 2009).

Os solos que tem menor porosidade são os arenosos. Como suas partículas são predominantemente grandes, a tendência é formar a disposição piramidal, que tem menor espaço vazio. Nas terras de textura fina, as partículas não se arranjam de maneira tão compactada, além disso, a argila coloidal contribui para formar agregados que aumentam a porosidade. Considera-se que, em média, a porosidade dos solos arenosos varia de 35 a $50 \%$ e dos argilosos de 40 a $60 \%$, e somente solos ricos em matéria orgânica apresentam porosidade entre 60 e $80 \%$ (RABELO, 2000).

O tamanho dos poros do solo pode variar, eles dependem das partículas e dos agregados. A distribuição dos espaços pode mudar pela atuação de alguma pressão ou rolamento das partículas. A quantidade, o tamanho, a distribuição e a continuidade são diferentes de um solo para outro (RESENDE et al., 2002).

A porosidade total é dividida em macroporos e microporos, sendo o solo um emaranhado de capilares de diferentes formas e tamanhos. Estes exercem grande influência na capacidade do solo em armazenar água. A perda da porosidade total esta relacionada diretamente com a compactação que reduz o tamanho dos poros (ANDRADE e SANTOS, 2004).

\subsection{Resistência mecânica do solo à penetração}

A resistência mecânica do solo à penetração é um parâmetro usado para verificar o grau de compactação do solo, que pode causar um impedimento físico na superfície e subsuperfície. Esta propriedade é influenciada pela textura, densidade e conteúdo de água (CAMARGO e ALLEONI, 1997).

A penetrometria consiste num método apropriado para avaliar a resistência mecânica à penetração das raízes no solo, devido à facilidade, rapidez e à possibilidade de efetuar grande 
número de repetições na obtenção de dados, embora possam ocorrer dificuldades na interpretação dos resultados obtidos devido à dependência desses em relação ao conteúdo de água, matéria orgânica e textura do solo (TAVARES FILHO et al., 1999).

O penetrômetro de impacto tem sido amplamente utilizado no campo para caracterizar a compactação provocada pelo uso e manejo do solo (TORMENA e ROLOFF, 1996), em razão do baixo custo, da não-necessidade de calibração freqüente e do fato de os resultados independerem do operador.

Os níveis críticos de resistência do solo para o crescimento das plantas variam com o tipo de solo e com a espécie cultivada (GENRO JUNIOR et al., 2004). Em geral, valores de resistência do solo à penetração, considerados críticos ao crescimento radicular, variam de 1,5 a 3,0MPa. Valores em torno de 2,5MPa são considerados baixos, ao passo que valores em torno de 3,5 a 6,5MPa, são considerados como valores capazes de causar problemas para o desenvolvimento radicular de leguminosas e gramíneas (TORRES e SARAIVA, 1999). Segundo Imhoff et al. (2000) valores de resistência mecânica do solo entre 2 e $3 \mathrm{MPa}$, são considerados limitantes ao desenvolvimento radicular.

\subsection{Matéria orgânica}

A importância da matéria orgânica nos solos é abrangente. Sua atuação se dá tanto na melhoria das condições físicas, tais como aeração, maior retenção e armazenamento de água, quanto nas propriedades químicas e físico-químicas, no fornecimento de nutrientes às plantas e na maior capacidade de troca catiônica do solo (CTC), além de proporcionar um ambiente adequado ao estabelecimento e à atividade da microbiota (FIGUEIREDO et al., 2008). Na Tabela 1 podemos visualizar os níveis de sustentabilidade de matéria orgânica e mais alguns atributos físicos, como: densidade do solo, porosidade total, resistência mecânica à penetração, sugerido por Goedert (2005). 
Tabela 1. Atributos do solo e níveis de sustentabilidade (GOEDERT, 2005).

\begin{tabular}{l|l}
\hline Atributo & Nível de sustentabilidade \\
\hline Densidade do solo & $<1,0 \mathrm{~g} \mathrm{~cm}^{-3}$ \\
Porosidade total & $>60 \mathrm{~cm}^{3} \mathrm{~cm}^{-3}$ \\
Resistência mecânica à penetração & $<1,0 \mathrm{MPa}$ \\
\hline & Textura argilosa: $>40 \mathrm{~g} \mathrm{~kg}^{-1}$ \\
Matéria orgânica & Textura média: $>30 \mathrm{~g} \mathrm{~kg}^{-1}$ \\
& Textura arenosa: $>20 \mathrm{~g} \mathrm{~kg}^{-1}$ \\
\hline
\end{tabular}




\section{MATERIAL E MÉTODOS}

O experimento foi conduzido em uma propriedade agrícola, localizada no município de Vale do São Domingos nas coordenadas S $15^{\circ} 36^{\prime} 329^{\prime \prime}$ e W0 5906'050” e altitude de 489 $\mathrm{m}$, em área caracterizada por relevo plano e solo apresentando características homogêneas. $\mathrm{O}$ clima da região é do tipo Aw segundo a classificação de Köppen, tropical, com chuvas concentradas no verão (outubro a abril), período seco bem definido durante o inverno (maio a setembro) e precipitação pluvial média anual de $1.500 \mathrm{~mm}$ e temperatura média de $27^{\circ} \mathrm{C}$. O solo do local é classificado como um Argissolo Vermelho (Embrapa, 1999), cujo a composição granulométrica na camada de $0,20 \mathrm{~m}$ é de $345,5 \mathrm{~g} \mathrm{~kg}^{-1}$ de argila, $98,5 \mathrm{~g} \mathrm{~kg}^{-1} \mathrm{de}$ silte e $556 \mathrm{~g} \mathrm{~kg}^{-1}$ de areia.

Os tratamentos corresponderam a um fatorial $3 \times 2 \times 2$ num delineamento experimental inteiramente casualisado com 4 repetições. Os fatores em estudo foram sistemas de pastejo, época de pastejo e camadas.

A área experimental era antes cultivada com Brachiaria brizantha cv. Marandú pastejada por bovinos em sistema de lotação contínua. Na instalação do experimento a área de 24 ha foi subdividida em três sistemas de produção, cada um com 8 ha.

Os sistemas de uso foram: Convencional (CC): formado exclusivamente pelo cultivar Piatã (Brachiaria brizantha cv. BRS Piatã), sem adubação anual de reposição, manejado em sistema de lotação contínua, constituído de quatro piquetes de 2 ha cada; Adubado (AD): constituído de quatro piquetes de 2 ha cada, sendo cada um destes piquetes subdivididos em quatro sub-piquetes com área de 0,5 ha cada, manejados em sistema de lotação rotacionado, considerando a altura como critério para a entrada $(40 \mathrm{~cm})$ e saída dos animais $(20 \mathrm{~cm})$ dos piquetes formado exclusivamente pelo cultivar Piatã (Brachiaria brizantha cv. BRS Piatã), com a adubação anual de reposição com N-P-K na proporção de 45-20-20 kg ha ${ }^{-1} \mathrm{ano}^{-1}$; e Consorciado (CS): constituído de quatro piquetes de 2 ha cada, sendo cada um destes piquetes subdivididos em quatro sub-piquetes com área de 0,5 ha cada, manejados em sistema de lotação rotacionado, considerando a altura como critério para a entrada $(40 \mathrm{~cm})$ e saída dos animais $(20 \mathrm{~cm})$ dos piquetes, formado pelo consórcio da gramínea (Brachiaria brizantha $\mathrm{cv}$. BRS Piatã) e leguminosa (Stylosanthes Campo Grande), recebendo adubação anual de reposição com N-P-K de 00-20-20 kg ha ${ }^{-1} \mathrm{ano}^{-1}$.

$\mathrm{Na}$ ocasião da instalação do experimento foram realizadas duas gradagens com grade aradora, seguida de uma gradagem com grade niveladora no início do período chuvoso. Após 
a realização do preparo do solo a semeadura foi realizada à lanço, na quantidade de $3,5 \mathrm{~kg} \mathrm{ha}^{-1}$ de sementes puras viáveis (SPV) de Brachiaria brizantha cv. BRS Piatã nos sistemas CC e AD e de 3,0 $\mathrm{kg} \mathrm{ha}^{-1}$ de SPV de Brachiaria brizantha $\mathrm{cv}$. BRS Piatã misturadas a 2,5 $\mathrm{kg} \mathrm{ha}^{-1} \mathrm{de}$ SPV de Stylosanthes Campo Grande no sistema CS.

A adubação utilizada no sistema AD foi constituída da aplicação de $100 \mathrm{~kg} \mathrm{ha}^{-1} \mathrm{do}$ formulado 00-20-20 no momento do plantio e $100 \mathrm{~kg} \mathrm{ha}^{-1}$ de uréia 90 dias após o plantio e no sistema CS foi realizada através da aplicação de $100 \mathrm{~kg} \mathrm{ha}^{-1}$ do formulado 00-20-20 no momento do plantio.

Todos os tratamentos foram pastejados por 24 animais da raça nelore (Bos taurus indicus L.), sendo colocados 2 animais por repetição, totalizando 8 animais em cada tratamento.

Em Abril de 2010, para avaliar o efeito do pisoteio animal nos sistemas foram coletados anéis com amostras de solo com estrutura indeformada nas camadas de 0,00 - 0,06 m e 0,06 0,12 m antes e após o pastejo. Estes anéis foram utilizados nas determinações de densidade do solo pelo método do anel volumétrico (BLAKE e HARTGE, 1986), macroporosidade, microporosidade e porosidade total, pelo método da mesa de tensão. Foram coletadas também amostras com estrutura deformada na mesma camada para a determinação do teor de matéria orgânica (EMBRAPA, 1997).

A resistência do solo à penetração foi determinada nas profundidades de $0,0-0,1,0,1$ 0,2, 0,2 - 0,3 e 0,3 - 0,4 m, com o penetrômetro de impacto (modelo IAA/ Planalsucar-Stolf), com ângulo de cone de $30^{\circ}$ e os resultados transformados segundo Stolf (1991).

Os resultados obtidos foram submetidos à análise de variância e quando significativos as médias foram comparadas pelo teste de Scott Knott a 0,005 de probabilidade de erro. 


\section{RESULTADOS E DISCUSSÃO}

A densidade do solo não foi significativamente alterada (Tabela 2). Mas pode-se observar que pós-pastejo a camada 0,00 - 0,06 m apresentou aumento da densidade do solo em todos os sistemas e a camada 0,06 - 0,12 m apresentou redução ou não teve mudança na densidade do solo comparando com o pré-pastejo. Já em relação aos tratamentos o sistema convencional apresentou em média menores densidades que os outros tratamentos. $\mathrm{O}$ fato de as alterações devido ao pastejo animal na densidade do solo se concentrar na camada de 0,00 - 0,06 m concorda com resultados de outros trabalhos realizados. A pressão exercida sobre o solo através do pisoteio animal é o agente causador da compactação e há evidências de que a compactação superficial está relacionada a essa pressão. Esses relatos ajudam a entender o fato de que a compactação do solo causada pelo pisoteio animal se concentra nas camadas mais superficiais, até 5,0 cm de profundidade (MORAES e LUSTOSA, 1997).

Tabela 2. Densidade do solo sob diferentes épocas de pastejo, sistemas de uso e camadas (m).

\begin{tabular}{c|c|c|c|c}
\hline \multicolumn{5}{c}{ Densidade do solo $\left(\mathrm{g} \mathrm{cm}^{-3}\right)$} \\
\hline Época & Camada $(\mathrm{m})$ & Convencional & Adubado & Consorciado \\
\hline \multirow{2}{*}{ Pré-Pastejo } & $0,00-0,06$ & $1,39^{\text {Aa } \alpha}$ & $1,40^{\text {Aa } \alpha}$ & $1,37^{\text {Aa } \alpha}$ \\
\cline { 2 - 5 } & $0,06-0,12$ & $1,39^{\text {Aa } \alpha}$ & $1,41^{\text {Aa } \alpha}$ & $1,42^{\text {Aa } \alpha}$ \\
\hline \multirow{2}{*}{ Pós-Pastejo } & $0,00-0,06$ & $1,43^{\text {Aa } \alpha}$ & $1,45^{\text {Aa } \alpha}$ & $1,43^{\text {Aa }}$ \\
\cline { 2 - 5 } & $0,06-0,12$ & $1,37^{\text {Aa } \alpha}$ & $1,40^{\text {Aa } \alpha}$ & $1,42^{\text {Aa } \alpha}$ \\
\hline
\end{tabular}

Letras maiúsculas $\left({ }^{\mathrm{AB}}\right)$ entre tratamentos na mesma época e camada;

Letras minúsculas $\left({ }^{\mathrm{ab}}\right)$ entre épocas no mesmo tratamento e camada;

Símbolos $\left({ }^{\alpha \gamma}\right)$ entre camada no mesmo tratamento e época;

A densidade do solo depende da natureza, das dimensões e da forma como se acham dispostas as partículas do solo. Nos solos argilosos os valores da densidade do solo oscilam de 1,00 a 1,25 $\mathrm{g} \mathrm{cm}^{-3}$ (SANTANA, 2009), e Camargo e Alleoni (1997) consideram crítico o valor de $1,55 \mathrm{~g} \mathrm{~cm}^{-3}$ em solos franco-argilosos a argilosos. Considerando esses valores podemos dizer que solos com densidade entre $1,25 \mathrm{~g} \mathrm{~cm}^{-3}$ à $1,55 \mathrm{~g} \mathrm{~cm}^{-3}$ são limitantes e valores densidade acima de $1,55 \mathrm{~g} \mathrm{~cm}^{-3}$ são críticos, sendo assim os valores de densidade da Tabela 1 , variando entre $1,37 \mathrm{~g} \mathrm{~cm}^{-3}$ à $1,45 \mathrm{~g} \mathrm{~cm}^{-3}$ podem ser limitantes ao desenvolvimento das raízes das gramíneas e leguminosas no perfil do solo, caracterizando solo compactado. Segundo Rabelo (2000) quanto mais elevada for a densidade do solo, maior será sua compactação, menor será a sua estruturação, menor a sua porosidade total e, 
conseqüentemente, maiores serão as restrições para o crescimento e desenvolvimento das plantas.

Azevedo e Sverzut (2007) encontraram que o uso do solo com pastagem propiciou a alteração dos atributos físicos da camada superficial, evidenciado pela compactação do solo, pois os valores de densidade do solo, microporosidade e resistência do solo à penetração do solo sob pastagem foram superiores, e no caso de porosidade total, macroporosidade e condutividade hidráulica foram inferiores.

Em relação aos atributos físicos macroporosidade, microporosidade e porosidade total, somente foi encontrada diferença significativa na microporosidade (Tabela 3).

Tabela 3. Macroporosidade, microporosidade e porosidade total sob diferentes épocas de pastejo, sistemas de uso e camadas (m).

\begin{tabular}{|c|c|c|c|c|}
\hline \multicolumn{5}{|c|}{ Macroporosidade $\left(\mathrm{cm}^{3} \mathrm{~cm}^{-3}\right)$} \\
\hline Época & Camada (m) & Convencional & Adubado & Consorciado \\
\hline \multirow{2}{*}{ Pré-Pastejo } & $0,00-0,06$ & $0,20^{\text {Aa } \alpha}$ & $0,18^{\text {Aa } \alpha}$ & $0,24^{\text {Aa } \alpha}$ \\
\hline & $0,06-0,12$ & $0,23^{\text {Aa } \alpha}$ & $0,20^{\text {Aa } \alpha}$ & $0,21^{\text {Aa } \alpha}$ \\
\hline \multirow{2}{*}{ Pós-Pastejo } & $0,00-0,06$ & $0,21^{\text {Aa } \alpha}$ & $0,20^{\text {Aa } \alpha}$ & $0,22^{\text {Aa } \alpha}$ \\
\hline & $0,06-0,12$ & $0,25^{\text {Aa } \alpha}$ & $0,26^{\text {Aa } \alpha}$ & $0,27^{\text {Aa } \alpha}$ \\
\hline \multicolumn{5}{|c|}{ Microporosidade $\left(\mathrm{cm}^{3} \mathrm{~cm}^{-3}\right)$} \\
\hline Época & Camada (m) & Convencional & Adubado & Consorciado \\
\hline \multirow{2}{*}{ Pré-Pastejo } & $0,00-0,06$ & $0,27^{\mathrm{Aa} \alpha}$ & $0,28^{\mathrm{Aa} \alpha}$ & $0,24^{\mathrm{Ba} \alpha}$ \\
\hline & $0,06-0,12$ & $0,24^{\text {Aa } \gamma}$ & $0,26^{\text {Aa } \alpha}$ & $0,25^{\mathrm{Aa} \alpha}$ \\
\hline \multirow{2}{*}{ Pós-Pastejo } & $0,00-0,06$ & $0,24^{\mathrm{Ab} \alpha}$ & $0,25^{\mathrm{Ab} \alpha}$ & $0,23^{\mathrm{Aa} \alpha}$ \\
\hline & $0,06-0,12$ & $0,23^{\mathrm{Aa} \alpha}$ & $0,21^{\mathrm{Ab} \gamma}$ & $0,19^{\mathrm{Ab} \gamma}$ \\
\hline \multicolumn{5}{|c|}{ Porosidade total $\left(\mathrm{cm}^{3} \mathrm{~cm}^{-3}\right)$} \\
\hline Época & Camada (m) & Convencional & Adubado & Consorciado \\
\hline \multirow{2}{*}{ Pré-Pastejo } & $0,00-0,06$ & $0,47^{\text {Aa } \alpha}$ & $0,47^{\text {Aa } \alpha}$ & $0,48^{\text {Aa } \alpha}$ \\
\hline & $0,06-0,12$ & $0,47^{\text {Aa } \alpha}$ & $0,46^{\text {Aa } \alpha}$ & $0,46^{\text {Aa } \alpha}$ \\
\hline \multirow{2}{*}{ Pós-Pastejo } & $0,00-0,06$ & $0,45^{\text {Aa } \alpha}$ & $0,45^{\text {Aa } \alpha}$ & $0,45^{\text {Aa } \alpha}$ \\
\hline & $0,06-0,12$ & $0,48^{\text {Aa } \alpha}$ & $0,47^{\text {Aa } \alpha}$ & $0,46^{\mathrm{Aa} \alpha}$ \\
\hline
\end{tabular}

Letras maiúsculas $\left({ }^{\mathrm{AB}}\right)$ entre tratamentos na mesma época e camada;

Letras minúsculas $\left({ }^{\mathrm{ab}}\right)$ entre épocas no mesmo tratamento e camada;

Símbolos $\left({ }^{\alpha \gamma}\right)$ entre camada no mesmo tratamento e época;

Conforme a Tabela 3 a microporosidade foi significativamente menor no sistema consorciado, na camada $0,00-0,06 \mathrm{~m},\left(\mathrm{CS}-0,24 \mathrm{~cm}^{3} \mathrm{~cm}^{-3}\right)$ que nos outros tratamentos na mesma época e camada (CC $-0,27 \mathrm{~cm}^{3} \mathrm{~cm}^{-3}$; AD $\left.-0,28 \mathrm{~cm}^{3} \mathrm{~cm}^{-3}\right)$. No mesmo tratamento e camada, a microporosidade nos sistemas convencional e adubado na camada de 0,00-0,06 m (CC - 0,24 $\mathrm{cm}^{3} \mathrm{~cm}^{-3}$; AD $-0,25 \mathrm{~cm}^{3} \mathrm{~cm}^{-3}$ ) e nos sistemas adubado e consorciado na camada de $0,06-0,12 \mathrm{~m}\left(\mathrm{AD}-0,21 \mathrm{~cm}^{3} \mathrm{~cm}^{-3} ; \mathrm{CS}-0,19 \mathrm{~cm}^{3} \mathrm{~cm}^{-3}\right)$ foram significativamente menores 
no pós-pastejo do que no pré-pastejo. Na mesma época e tratamento, no pré-pastejo do sistema convencional a microporosidade na camada $0,06-0,12 \mathrm{~m}\left(\mathrm{CC}-0,24 \mathrm{~cm}^{3} \mathrm{~cm}^{-3}\right)$ foi significativamente menor que na camada $0,00-0,06 \mathrm{~m}$, enquanto que no pós-pastejo dos sistemas adubado e consorciado a microporosidade na camada $0,06-0,12 \mathrm{~m}\left(\mathrm{AD}-0,21 \mathrm{~cm}^{3}\right.$ $\mathrm{cm}^{-3} ; \mathrm{CS}-0,19 \mathrm{~cm}^{3} \mathrm{~cm}^{-3}$ ) foi significativamente menor que na camada $0,00-0,06 \mathrm{~m}$.

Embora a macroporosidade e a porosidade total não terem apresentado resultados significativos, seus valores variaram (Tabela 3). Em relação à macroporosidade no póspastejo teve aumento dos valores, exceto na camada 0,00 - 0,06 $\mathrm{m}$ do sistema consorciado que no geral apresentou maior macroporosidade. Já em relação à porosidade total na camada 0,00 - 0,06 m teve redução no pós-pastejo e na camada $0,06-0,12 \mathrm{~m}$ teve aumento, exceto no consorciado que não teve alteração. Isso pode ser explicado ao fato de que a pressão exercida sobre o solo através do pisoteio animal se concentra na camada superficial do solo (Moraes e Lustosa, 1997), deixando a camada subsuperficial do solo mais solta.

Considera-se que, em média, a porosidade dos solos argilosos seja de 40 a $60 \%$ (RABELO, 2000). A porosidade total obtida variando entre $45 \%$ a $48 \%$ está adequada, tendo suficiente espaço poroso.

$\mathrm{Na}$ Tabela 4 estão os valores de matéria orgânica presente nos diferentes sistemas de uso e camadas do solo, e observa-se que no sistema adubado a quantidade de matéria orgânica foi significativamente menor na camada $0,06-0,12 \mathrm{~m}\left(\mathrm{AD}-1,27 \mathrm{dag} \mathrm{kg}^{-1}\right.$ ) comparando com a camada $0,00-0,06 \mathrm{~m}\left(1,62 \mathrm{dag} \mathrm{kg}^{-1}\right)$ do mesmo tratamento.

Tabela 4. Teor médio de matéria orgânica sob diferentes sistemas de uso e camadas.

\begin{tabular}{c|c|c|c}
\hline \multicolumn{4}{c}{ Matéria orgânica $\left(\right.$ dag kg $\left.^{-1}\right)$} \\
\hline Camada $(\mathrm{m})$ & Convencional & Adubado & Consorciado \\
\hline $0,00-0,06$ & $1,40^{\mathrm{Aa}}$ & $1,62^{\mathrm{Aa}}$ & $1,50^{\mathrm{Aa}}$ \\
\hline $0,06-0,12$ & $1,20^{\mathrm{Aa}}$ & $1,27^{\mathrm{Ab}}$ & $1,32^{\mathrm{Aa}}$ \\
\hline
\end{tabular}

Letras maiúsculas $\left({ }^{\mathrm{AB}}\right)$ entre tratamentos na mesma camada;

Letras minúsculas $\left({ }^{\mathrm{ab}}\right)$ entre camadas no mesmo tratamento;

Em relação à matéria orgânica (Tabela 4) pode-se observar que os maiores teores ocorreram na camada de 0,00 - 0,06 m. Justifica-se tal diferença entre as camadas pela presença de grande quantidade de raízes das gramíneas que se acumulam próximo da superfície (SALTON et al., 2002). A semelhança no teor de matéria orgânica entre os sistemas é devido ao comportamento das gramíneas que são excelentes incorporadoras de matéria orgânica no solo. 
Estatisticamente não houve diferença significativa na resistência do solo à penetração entre épocas e tratamentos (Figuras 1 e 2).

Segundo Imhoff et al. (2000) valores de resistência mecânica do solo acima de 2 MPa, são considerados limitantes ao desenvolvimento radicular. Quando a resistência à penetração é menor do que 1,1 MPa não há limitação ao crescimento radicular, sendo o solo considerado como de muito baixa resistência, enquanto que para valores entre 1,0 e 2,5 $\mathrm{MPa}$, a resistência deve ser considerada baixa, ocorrendo pouca limitação ao crescimento radicular (CAMARGO e ALLEONI, 1997). Tormena et al. (1998) afirmam que a resistência a penetração acima de 2,0 MPa é considerada impeditiva ao crescimento das raízes no solo.

Considerando que a resistência do solo à penetração acima de 2 MPa começa a ser restritiva ao crescimento de raízes no perfil do solo, o sistema consorciado no pré-pastejo foi o único que não ofereceu resistência à penetração de raízes no perfil do solo, com valores entre 1,85 MPa a 2,01 MPa (Figura 1), isso é explicado devido ao fato de as raízes de gramíneas e leguminosas terem diâmetros diferentes, proporcionando maior espaço poroso e deixando o solo mais solto. Já na Figura 2 observa-se que pós-pastejo na camada superficial até $5 \mathrm{~cm}$ de profundidade ocorreu leve resistência $(2,5 \mathrm{~cm}-2,28 \mathrm{MPa} ; 5 \mathrm{~cm}-2,18 \mathrm{MPa})$ demonstrando que o pisoteio animal provoca alterações nas camadas superficiais do solo.

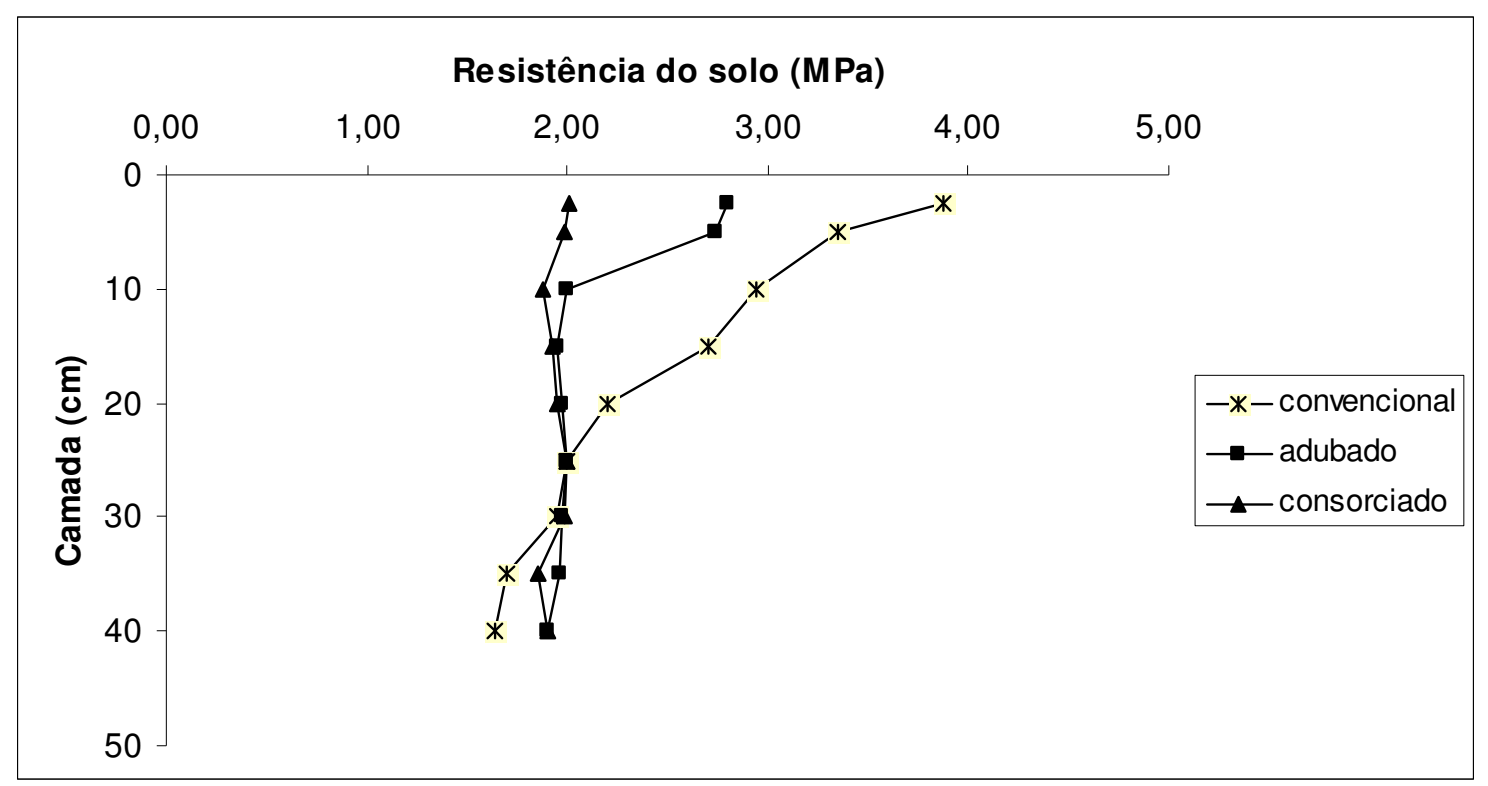

Figura 1. Resistência do solo à penetração (MPa) pré-pastejo sob diferentes sistemas de uso e camadas.

O sistema adubado no pré-pastejo (Figura 1) ofereceu resistência à penetração nos primeiros $5 \mathrm{~cm}$ do perfil do solo $(2,5 \mathrm{~cm}-2,8 \mathrm{MPa} ; 5 \mathrm{~cm}-2,74 \mathrm{MPa})$, sendo limitante ao 
crescimento de raízes, caracterizando solo compactado, apesar de ser o sistema com maior quantidade de matéria orgânica nos primeiros $6 \mathrm{~cm}$. Abaixo dos $5 \mathrm{~cm}$ a resistência do solo decaiu mantendo-se próximo de $2 \mathrm{MPa}$ abaixo dos $10 \mathrm{~cm}$. Já no pós-pastejo (Figura 2) a resistência do solo foi até $15 \mathrm{~cm}$ de profundidade (entre 2,45 $\mathrm{MPa}$ e 2,98 $\mathrm{MPa}$ ) e abaixo dos $15 \mathrm{~cm}$ se manteve ao redor de $2 \mathrm{MPa}$, o que é interpretado que o pisoteio animal foi o causador do aumento da resistência do solo, já que neste sistema não tinha consorcio com leguminosa, acarretando maior densidade.

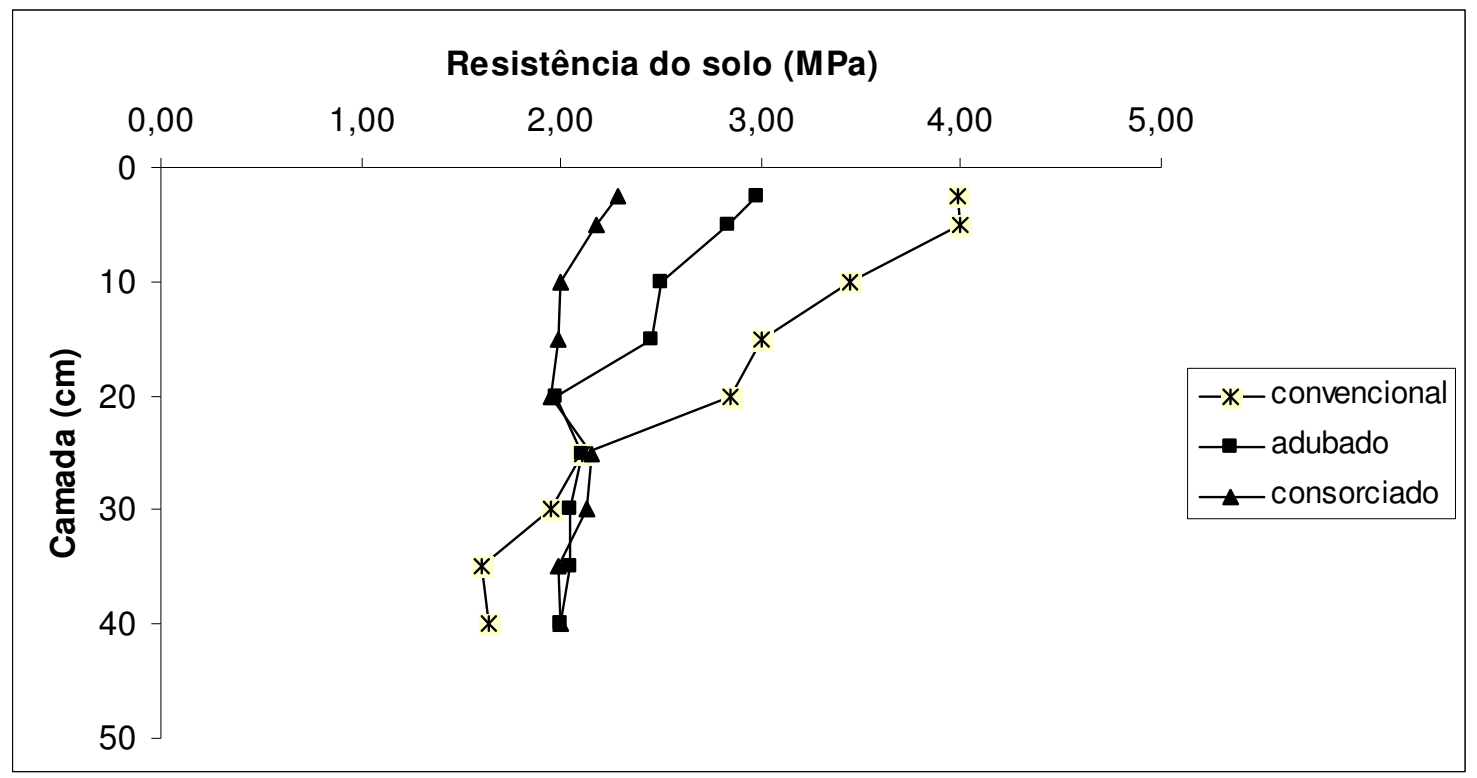

Figura 2. Resistência do solo à penetração $(\mathrm{MPa})$ pós-pastejo sob diferentes sistemas de uso e camadas

Os sistemas adubado e consorciado se comportaram relativamente próximos abaixo dos $20 \mathrm{~cm}$ de profundidade, sendo próximos de $2 \mathrm{MPa}$ nas duas épocas de amostragem (Figuras 1 e 2).

O sistema convencional foi o que ofereceu maior resistência do solo à penetração de raízes, sendo prejudicial até $20 \mathrm{~cm}$ do perfil do solo, tanto no pré-pastejo como no pós-pastejo (Figuras 1 e 2), pois se manteve acima de 2,2 $\mathrm{MPa}$ que é considerado impeditivo ao crescimento de raízes. Esta resistência é explicada em pastejo contínuo pelo fato dos animais permanecerem durante todo o tempo no mesmo piquete, não tendo período de descanso e também pelo crescimento da gramínea ser em touceiras proporciona áreas descobertas de solo tendo maior impacto da pressão dos cascos dos animais no solo e consequentemente maior tendência a compactação, sendo confirmada pelo pós-pastejo a resistência à penetração ter sido maior que no pré-pastejo. Abaixo dos $20 \mathrm{~cm}$ a resistência do solo decaiu gradativamente 
até que abaixo dos $25 \mathrm{~cm}$ teve menor resistência que os outros dois sistemas. Essa característica do sistema convencional na camada subsuperficial oferecer menor resistência que os outros dois sistemas é explicada pelo fato de que o pastejo constante dos animais nesse piquete exerce maior pressão na camada superficial do solo.

De acordo com Alvarenga et al. (1996) à medida que a compactação do solo aumenta, há uma situação de decréscimo na porosidade total, assim, na medida em que aumenta a densidade do solo, aumenta a limitação ao crescimento radicular e o armazenamento de água no solo é reduzido especialmente nas situações de maior compactação. Isso é observado na camada 0,00 - 0,06 m, que no geral a densidade do solo aumentou e a porosidade total diminuiu no pós pastejo, e na camada 0,06 - 0,12 $\mathrm{m}$ aconteceu o contrário, confirmando o fato de que a maior pressão exercida pelo pisoteio animal é na camada superficial, exceto para os valores de resistência do solo à penetração no sistema convencional que tinha lotação contínua dos animais na pastagem e propiciou camada compactada até próximo dos $25 \mathrm{~cm}$ de profundidade. 


\section{CONCLUSÃO}

O pisoteio animal alterou somente a microporosidade do solo, ao contrário do que se tem na literatura, em que o pisoteio animal altera a macroporosidade. Sendo assim, pode-se concluir que este fato pode ter ocorrido devido que o solo estava muito seco e, neste caso, a microporosidade é mais facilmente alterada do que a macroporosidade.

A utilização de diferentes sistemas de pastejo não promoveu diferenças em relação ao teor de matéria orgânica.

Os solos do sistema de pastejo convencional apresentaram maior tendência à compactação do solo avaliada pela resistência mecânica a penetração de raízes. 


\section{REFERÊNCIAS}

ABREU, S. L. Propriedades hídricas e mecânicas afetadas por sistemas de manejo e variabilidade espacial de um Argissolo. 2000. 65p. Dissertação (Mestrado em Agronomia), Programa de pós-graduação em Agronomia, Universidade Federal de Santa Maria, Santa Maria, 2000.

ABREU, S. L.; REICHERT, J. M.; REINERT, D. J. Escarificação mecânica e biológica para a redução da compactação em argissolo franco-arenoso sob plantio direto. Revista Brasileira de Ciência do Solo, v. 28, p. 519-531, 2004.

ALBUQUERQUE, J. A.; REINERT, D. J. Densidade radicular do milho considerando os atributos de um solo com horizonte B textural. Revista Brasileira de Ciência do Solo, Viçosa, v.25, n.3, p. 539-549, 2001a.

ALBUQUERQUE, J. A.; SANGOI, L.; ENDER, M. Efeito da integração lavoura pecuária nas propriedades físicas do solo e características da cultura do milho. Revista Brasileira de Ciência do Solo, Lages, v. 25, p. 717-723, 2001 b.

ALVARENGA, R. C. et al. Crescimento de leguminosas em camadas de solo compactadas artificialmente. Revista Brasileira de Ciência do Solo, Campinas, v. 20, n. 2, p. 319-326, maio/ ago. 1996.

ANDRADE, C. E. ; SANTOS, M. F. P. Manejo do solo visando maior disponibilidade de água para a cultura do café. In: ZAMBOLIN, L. Efeitos da irrigação sobre a qualidade e produtividade do café. Viçosa: UFV, 2004. p. 385-416.

ANDRADE, C. L. T. et al. Parâmetros de solo-água para a engenharia de irrigação e ambiental. In: CONGRESSO BRASILEIRO DE ENGENHARIA AGRÍCOLA, 27, 1998, Lavras. Anais... Lavras:UFLA/SBEA, 1998. p.1-132.

AZEVEDO, E. C. de; SVERZUT, C. B. Alterações dos atributos físicos e químicos do solo sob pastagem no sudoeste do estado de Mato Grosso. Revista de Agricultura Tropical, Cuiabá, v. 9, n. 1, 2007.

BERTOL, I. et al. Propriedades físicas do solo relacionadas a diferentes níveis de ofertas de forragem de capim-elefante anão cv. Mott. Pesquisa Agropecuária Brasileira, Brasília, v. 35 , n. 5, p. 1047-1054, maio 2000. 
BERTOL, I.; MAFRA, A. L.; COGO, N. P. Conservação do solo em pastagens. In: PEDREIRA, C. G. S.; MOURA, J. C.; SILVA, S. C.; FARIA, V. P. As pastagens e o meio ambiente: Anais do $23^{\circ}$ simpósio sobre manejo da pastagem. Piracicaba: FEALQ, 2006. p. 139-163.

BEUTLER, A. N.; CENTURION, J. F.; SILVA, A. P. Intervalo hídrico ótimo e a produção de soja e arroz em dois latossolos. Irriga, Botucatu, v. 9, n. 2, p. 181-192, 2004.

BLAKE, G.R.; HARTGE, K. H.Bulk density. IN: KLUTE, A. (Ed). Methods of soil analysis. 2. ed. Madison: American Society of Agronomy/ Soil Science Society of América, 1986. Part. 1, p. 363-375. (Agronomy Monography, 9).

BRAIDA, J. A. et al. Relações entre a quantidade de palha existente sobre o solo e a densidade máxima obtida no ensaio Proctor. In: REUNIÃO BRASILEIRA DE MANEJO E CONSERVAÇÃO DO SOLO E DA ÁGUA, 15, 2004, Santa Maria, Anais... Santa Maria: Sociedade Brasileira de Ciência do Solo, 2004. CD-ROM

CAMARGO O. A.; ALLEONI, L. R. F. Conceitos gerais de compactação do solo, 2006. Disponível em: <http://www.infobibos.com/Artigos/CompSolo/Comp1.htm>. Acesso em: 05/06/2010.

CAMARGO, O. A.; ALLEONI, L. R. F. Compactação do solo e o desenvolvimento das plantas. Piracicaba, Escola Superior de Agricultura Luiz de Queiroz, 1997. 132p.

CASSOL, L. C. Relação solo-planta-animal num sistema de integração lavoura-pecuária em semeadura direta com calcário na superfície. 2003. 157p. Tese (Doutorado em Ciência do Solo), Departamento de Agronomia, Universidade Federal do Rio Grande do Sul, Porto Alegre, 2003.

CORREA, J. C.; REICHARDT, K. Efeito do tempo de uso das pastagens sobre as propriedades de um Latossolo Amarelo da Amazônia Central. Pesquisa Agropecuária Brasileira, v. 30, p. 107-114, 1995.

COSTA, O. V. Impacto animal sobre o componente abiótico do solo: ciclagem de nutrientes e compactação. (Revisão bibliográfica Forragicultura). UFV, Viçosa, MG, junho de 2000 .

DA SILVA, A. P.; et al. Qualidade física de solos sob sistemas intensivos de pastejo rotacionado. In: SIMPÓSIO SOBRE MANEJO DE PASTAGEM, Inovações tecnológicas no manejo de pastagens 19, 2002, Piracicaba. Anais... Piracicaba: FEALQ, 2002. p. 79-97. 
DIAS JÚNIOR, M. S.; PIERCE, F. J. O processo de compactação do solo e a sua modelagem. Revista Brasileira de Ciência do Solo, Viçosa, v. 20, n. 2, p. 175-182, 1996.

DIAS, L. E.; MELLO, J. W. V. de. Recuperação de áreas degradadas. Viçosa: UFV, Departamento de Solos; SOBRADE, 1998. 251p.

DIAS-FILHO, M. B.. Pastagens cultivadas na Amazônia Oriental Brasileira: processos e causas da degradação e estratégias de recuperação. In: DIAS, L. E.; MELLO, J. W. V. (eds.). Recuperação de áreas degradadas. Viçosa, Sociedade Brasileira de Recuperação de Áreas Degradadas, Universidade Federal de Viçosa, Departamento de Solos, 1998. p.135-147.

EMBRAPA. Centro Nacional de Pesquisa de Solos. Sistema brasileiro de classificação de solos. Brasília: Embrapa Produção de Informação; Rio de Janeiro: Embrapa Solos, 1999. 412 p.

EMBRAPA. Centro Nacional de Pesquisa de Solos. Manual e métodos de análise de solo. Rio de Janeiro: Ministério da Agricultura e do Abastecimento, 1997. 212 p.

FERNANDES, H. C.; SOUZA, A. P. Compactação dos solos florestais: uma questão de estudo. Revista Árvore, Viçosa, v. 25, n. 3, p. 387-392, 2001.

FIDALSKI, J. et al. Qualidade física do solo em pastagem adubada e sob pastejo contínuo. Pesquisa Agropecuária Brasileira, Brasília, v. 43, n. 11, p. 1583-1590, novembro 2008.

FIGUEIREDO, C. C.; RAMOS, M. L. G; TOSTES, R. Propriedades físicas e matéria orgânica de um latossolo vermelho sob sistemas de manejo e cerrado nativo. Biosci. J., Uberlândia, v. 24, n. 3, p. 24-30, jul./set. 2008.

FLORES, J. P. C. Atributos de solo e rendimento de soja em um sistema de integração lavoura-pecuária com diferentes pressões de pastejo em plantio direto com aplicação de calcário na superfície. 2004. 74p. Dissertação (Mestrado em Ciência do Solo), Departamento de Agronomia Universidade Federal do Rio Grande do Sul, Porto Alegre , 2004.

FLORES, J. P. C. Atributos físicos do solo e rendimento de soja em sistema plantio direto em integração lavoura pecuária com diferentes pressões de pastejo. Revista Brasileira de Ciência do Solo, Viçosa, v. 31, n. 4, p. 771-780, jul./ago. 2007.

FREITAS, P. L. Aspectos físicos e biológicos do solo. In: LANDERS, J. N. Experiências de plantio direto no Cerrado. Goiânia: APDC, 1994. p. 199-213. 
GENRO JÚNIOR, S. A.; REINERT, D. J.; REICHERT, J. M. Variabilidade temporal da resistência à penetração de um Latossolo argiloso sob semeadura direta com rotação de culturas. Revista Brasileira de Ciência do Solo, v. 28, p. 477-484, 2004.

GIAROLA, N. F. B.; TORMENA, C. A.; DUTRA, A. C. Degradação física de um Latossolo Vermelho utilizado para produção intensiva de forragem. Revista Brasileira de Ciência do Solo, Viçosa, v. 31, n. 5, p. 863-873, 2007.

GOEDERT, W. Qualidade do solo em sistema de produção agrícola. IN: CONGRESSO BRASILEIRO DE CIÊNCIA DO SOLO, 2005, Recife. SBCS, v. 1, p. 1-200.

IMHOFF, S.; SILVA, A. P. da; TORMENA, C. A. Aplicações da curva de resistência no controle da qualidade física de um solo sob pastagem. Pesquisa Agropecuária Brasileira, Brasília, v. 35, n. 7, p. 1493-1500, 2000.

LANZANOVA M. E. et al. Atributos físicos do solo em sistema de integração lavourapecuária sob plantio direto. Revista Brasileira de Ciência do Solo, Santa Maria, v. 31, p. 1131-1140, 2007.

LEÃO, T. P. et al. Intervalo hídrico ótimo em sistemas de pastejo contínuo e rotacionado. In: CONGRESSO BRASILEIRO DE CIÊNCIA DO SOLO, 29, 2003, Viçosa. Anais... Viçosa: Sociedade Brasileira de Ciência do Solo, 2003. 4p. CD-ROM.

LEONEL, C. L. et al. Comportamento de forrageiras em diferentes graus de compactação no Latossolo Vermelho Amarelo Distrófico textura argilosa. In: CONGRESSO BRASILEIRO DE CIÊNCIA DO SOLO, 29, 2003, Viçosa, Anais... Viçosa: Sociedade Brasileira de Ciência do Solo. 2003. 4p. CD-ROM.

LIMA, C. L. R. et al. Compressibilidade de um solo sob sistemas de pastejo rotacionado intensivo irrigado e não-irrigado. Revista Brasileira de Ciência do Solo, v. 28, p. 945-951, 2004.

MACEDO, M. C. M.; KICHEL, A. N.; ZIMMER, A. H. Degradação e alternativas de recuperação e renovação de pastagens. Comunicado técnico, Campo Grande: EMBRAPA, n. 62 , novembro 2000. 4 p.

MELLO, N. A. Degradação física dos solos sob integração lavoura pecuária. In: ENCONTRO DE INTEGRAÇÃO LAVOURA-PECUÁRIA NO SUL DO BRASIL, 1, 2002, Pato Branco. Anais... Pato Branco, 2002. p. 43-60. 
MENDES, F. G.; MELLONI, E. G. P.; MELLONI, R. Aplicação de atributos físicos do solo no estudo da qualidade de áreas impactadas em Itajubá-MG. Revista Cerne, Lavras, v. 12, n. 3, p. 211-220, jul./set. 2006.

MORAES, A.; LUSTOSA, S. B. C. Efeito do animal sobre as características do solo e a produção da pastagem. In: SIMPÓSIO SOBRE AVALIAÇÃO DE PASTAGENS COM ANIMAIS, 1997, Maringá. Anais... Maringá: Universidade Estadual de Maringá, 1997. p. 129-149.

MULLER, M. M. L. Degradação de pastagens na Região Amazônica: propriedades físicas do solo e crescimento de raízes. Pesquisa Agropecuária Brasileira, Brasília, v. 36, n. 11, p. 1409-1418, 2001.

NASCIMENTO Jr. Ecossistemas de pastagens cultivadas. In: SIMPÓSIO SOBRE MANEJO DE PASTAGENS, 15, 1998, Piracicaba. Anais... Piracicaba: FEALQ, 1998. p. 271-296.

OLIVEIRA NOBRE, N. A. de. Avaliação dos atributos físicos do solo em três sistemas de uso e seus impactos na bacia hidrográfica do Rio Carapá em Colíder-MT. 2008. 109 p. Dissertação (Mestrado em Ciências Ambientais), Universidade do Estado de Mato Grosso, Cáceres, 2008.

PRIMAVESI, A. Manejo ecológico de pastagens em regiões tropicais e subtropicais. 5 ed. São Paulo: Nobel, 1999. p.10-16.

RABELO, N. A. Método de Análise (Cadernos Didáticos; 12) Goiânia: Ed. UCG, 2000. 88p.

REICHERT, J. M.; REINERT, D. J.; BRAIDA, J. A. Qualidade do solo e sustentabilidade: de sistemas agrícolas. Revista Ciência e Ambiente, Ed. 27, p. 29-48, 2003.

RESENDE, M. et al. Pedologia: base para distinção de ambientes. 4 ed. Viçosa: NEPUT, 2002. 338p.

RODRIGUES JUNIOR; D.J. et al. Compactação do solo e o pisoteio bovino numa pastagem com e sem irrigação. II Seminário Iniciação Científica - Instituto Federal de Educação e Tecnologia Triângulo Mineiro, Campus Uberaba, MG. 20 de outubro de 2009.

ROSOLEM, C. A. et al. Sistema radicular e nutrição do milho em função da calagem e da compactação do solo. Revista Brasileira de Ciência do Solo, v. 18, p.491-497, 1994. 
ROTH, C. H.; CASTRO-FILHO, C.; MEDEIROS, G. B. Análise de fatores físicos e químicos relacionados com a agregação de um Latossolo Roxo distrófico. Revista Brasileira de Ciência do Solo, v. 15, p. 241-248, 1992.

SALTON, J.C. et al. Pastoreio de aveia e compactação do solo. Revista Plantio Direto, v. 69, p. 32-34, 2002.

SANTANA, S. C. Indicadores físicos da qualidade de solos no monitoramento de pastagens degradadas na região sul do Tocantins. 2009. 76 p. Dissertação (Mestrado em Produção Vegetal), Universidade Federal do Tocantins, Gurupi, 2009.

SARMENTO, P. et al. Atributos químicos e físicos de um Argissolo cultivado com Panicum maximum Jacq. cv. IPR-86 Milênio, sob lotação rotacionada e adubado com nitrogênio. Revista Brasileira de Ciência do Solo, v. 32, p. 183-193, 2008.

SILVA, A. J. N. Alterações físicas e químicas de um Argissolo Amarelo Coeso sob diferentes sistemas de manejo com cana-de-açúcar. 2003. 120p. Tese (Doutorado em Ciência do Solo). Universidade Federal do Rio Grande do Sul, Porto Alegre, 2003.

SILVA, G. J.; MAIA, J. C. S.; BIANCHINI, A. Crescimento da parte aérea de plantas cultivadas em vaso, submetidas a irrigação subsuperficial e a diferentes graus de compactação de um Latossolo Vermelho-Escuro distrófico. Revista Brasileira de Ciência do Solo, v. 30, p. 31-40, 2006.

SILVA, V. R.; REINERT, D.; REICHERT, J. M. Densidade do solo, atributos químicos e sistema radicular do milho afetados pelo pastejo e manejo do solo. Revista Brasileira de Ciência do Solo, v. 24, p. 191-199, 2000.

STOLF, R. Teoria e teste experimental de fórmulas de transformação de dados de penetrômetro de impacto em resistência do solo. Revista Brasileira de Ciência do Solo, Campinas, v.15, n.3, p.229-35, 1991.

STONE, L. F.; GUIMARÃES, C. M.; MOREIRA, J. A. A. Compactação do solo na cultura do feijoeiro: I. efeitos nas propriedades físico-hídricas do solo. Revista Brasileira de Engenharia Agrícola e Ambiental, Campina Grande, v. 6, n. 2, p.207-212, 2002.

TAVARES FILHO, J.; EIRA, G. C.; LUDWIG, L. R. F Avaliação da compactação em um solo cultivado no sistema convencional. Engenharia Agrícola, Jaboticabal, v. 19, p. 219-225, 1999. 
TAVARES FILHO, J.; RIBON, A. A. Resistência do solo à penetração em resposta ao número de amostras e tipo de amostragem. Revista Brasileira de Ciência do Solo, v. 32, p. 487-494, 2008.

TAVARES FILHO, J.;GRIMALDI, M.; TESSIER, D. Compressibilidade de agregados de um latossolo amarelo da amazônia em resposta ao potencial da água do solo. Revista Brasileira de Ciência do Solo, v. 29, p. 489-495, 2005.

TORMENA, C. A. et al. Propriedades físicas e taxa de estratificação de carbono orgânico num Latossolo Vermelho após dez anos sob dois sistemas de manejo. Revista Brasileira de Ciência do Solo, Viçosa, v. 28, n. 6, p. 1023-1031, 2004.

TORMENA, C. A. et al. Variação temporal do intervalo hídrico ótimo de um latossolo vermelho distroférrico sob sistemas de plantio direto. Revista Brasileira de Ciência do Solo, v. 31, p. 211-219, 2007.

TORMENA, C. A.; ROLOFF, G. Dinâmica da resistência à penetração de um solo sob plantio direto. Revista Brasileira de Ciência do Solo, Campinas, v. 20, n. 2, p. 333-339, 1996.

TORMENA, C. A.; SILVA, A. P.; LIBARDI, P. Caracterização do intervalo hídrico ótimo de um Latossolo Roxo sob plantio direto. Revista Brasileira de Ciência do Solo, Viçosa, v. 22, n. 4, p. 573-581, 1998.

TORRES, E.; SARAIVA, O. F. Camadas de impedimento do solo em sistemas agrícolas com a soja. Circular Técnica, 23. Londrina: Empresa Brasileira de Pesquisa Agropecuária, 1999. 58p.

TREIN, C. R.; COGO, N. P.; LEVIEN, R. Métodos de preparo do solo na cultura do milho e ressemeadura do trevo, na rotação aveia + trevo/milho, após pastejo intensivo. Revista Brasileira de Ciência do Solo, v. 15, p. 105-111, 1991. 